\title{
O SUJEITO E AS LEIS NA DESTITUIÇÃO DO PODER FAMILIAR
}

\author{
Subject and Laws in Dismissal of Family Power
}

El Sujeto y las Leyes en la Destitución del Poder Familiar

Artigo Original

\author{
Le Sujet et les Lois dans la Destitution du Pouvoir Familier
}

\section{Resumo}

A destituição do Poder Familiar constitui-se medida jurídica que impõe grande desafio aos profissionais do Direito. O diálogo com outros campos do saber pode auxiliar a pensar a destituição de forma a ampliar as discussões sobre esse estatuto. Este trabalho baseia-se na interlocução entre o Direito e a Psicanálise, analisando a relação do sujeito com as leis no contexto da destituição do Poder Familiar. Foram abordadas questões relativas à dimensão da Lei, como lei fundante e estruturante do sujeito, e das leis, as "leis escritas", com toda a complexidade, errância e carência que podemos constatar. Nessa relação, evidenciam-se a violência e a tirania das leis, os aspectos relacionados à utilização perversa da lei, à destituição subjetiva e ao posicionamento do sujeito frente aos estatutos normativos. Recorrendo a Antígona, a dimensão trágica do sujeito é evocada, o sujeito é convocado a responder por sua posição, quer esta tenha sido a de validar em ato a injunção inconsciente, quer tenha sido a de recuar diante dela. Antígona fala da autonomia do sujeito quando este, agora não mais alienado ao Outro, pode subjetivar seu desejo, indo de encontro àquilo que considera injusto ou não-humano, mesmo que inscrito numa tal "legalidade". O estudo se dá no sentido de uma ética psicanalítica e de como o sujeito pode ser apreendido em sua dimensão desejante no Direito. A destituição do Poder Familiar pode significar, para alguns, a desapropriação de si em sua paternidade e maternidade, a "destruição" de laços e vínculos que poderiam ser preservados através de medidas de cuidado à família; para outros, é a possibilidade de inscrição simbólica, pela instauração de uma Lei que os inscreve no humano.

Palavras-chave: psicanálise; sujeito; leis; ética da psicanálise; poder familiar.

\section{Abstract}

The removal of the Family Power constitutes legal measure imposing a great challenge to legal professionals. The dialogue with other fields of knowledge can help to think of dismissal in order to broaden the discussion on this statute. This work is based on dialogue between Law and Psychoanalysis, analyzing the subject's relation to the laws in the context of the dismissal of the Family Power. Issues were addressed on the dimension of the law, as the fundamental and structural law of the subject; and laws, "written laws" with all the complexity, wandering and need that we could see. In this relationship, the violence and tyranny of the laws, the aspects related to the perverse use of the law, subjective destitution and the positioning of the subject facing the regulatory statutes are highlighted. Using the Antigone, the tragic dimension of the subject is mentioned, the subject is called to answer for his position, whether this has been to validate act on the unconscious injunction, whether it was to retreat in front of her. Antigone talks about the autonomy of the subject now no longer alienated to the other, it can subjectify his desire, meeting what he considers unfair or non-human, even if it is enrolled in such "legality". The study is in the sense of a

\section{Suziani de Cássia Almeida Lemos $^{(1)}$ \\ Anamaria Silva Neves ${ }^{(2)}$ João Luiz Leitão Paravidini ${ }^{(3)}$}

1) Mestre em Psicologia Universidade Federal de Uberlândia. Atua na docência e coordenação do Curso de Psicologia do Instituto Luterano de Ensino Superior ILES/ULBRA Itumbiara-GO.

2) Pós-Doutorado no CWASU - Child and Woman Abuse Studies Unit. Professora associado 1 no curso de Psicologia da Universidade Federal de Uberlândia.

3) Pós-Doutorado pela Universidade Federal de Minas Gerais e PósDoutorado pela Faculdade de Medicina de São José do Rio Preto. Professor Associado da Universidade Federal de Uberlândia e da Prefeitura Municipal de Uberlândia. 
psychoanalytic ethics and how the subject can be grasped in its desiring dimension in Law. The removal of the Family Power may mean for some expropriation of themselves in their parenthood and the "destruction" of ties and bonds that could be preserved by family through caring measures, for others it is the possibility of symbolic inscription by setting a law that inscribes them in human.

Keywords: psychoanalysis; subject; laws; ethics of psychoanalysis; power family.

\section{Resumen}

La destitución del Poder Familiar constituye medida jurídica que impone un gran desafio a los profesionales del Derecho. El dialogo con otros campos del saber puede ayudar a pensar la destitución de forma que amplifique las discusiones acerca de este estatuto. Este trabajo está basado en la interlocución entre el Derecho y la Psicoanálisis, analizando la relación del sujeto con las leyes en el contexto de la destitución del Poder Familiar. Fueron planteadas cuestiones relativas a la dimensión de la Ley, como ley constructora y estructuradora del sujeto; y de las leyes, las "leyes escritas" con toda la complexidad, errancia y carencia que podemos constatar. En esta relación, se evidencian la violencia y la tiranía de las leyes, los aspectos relacionados a la utilización perversa de la ley, a la destitución subjetiva y al posicionamiento del sujeto ante los estatutos normativos. Recurriendo a Antígona, es evocada la dimensión trágica del sujeto. El sujeto es convocado a contestar por su posición, sea esta la de validar en hecho la orden inconsciente, sea la de retroceder ante ella. Antígona habla de la autonomía del sujeto cuando este, ahora ya no más alienado al otro, puede subjetivar su deseo, yendo en dirección a aquello que piensa ser injusto o deshumano, aunque esté inscrito en la "legalidad". La investigación ocurre en el sentido de una ética psicoanalítica y de como el sujeto puede ser tomado en su dimensión deseable en el Derecho. La destitución del Poder Familiar puede significar para algunos el desapropiamiento de sí mismo en su paternidad y maternidad, la "destrucción" de lazos y relaciones que podrían ser preservados con medidas de cuidado a la familia, para otros es la posibilidad de inscripción simbólica, por la implementación de una Ley que les inscriba en el humano.

Palabras clave: psicoanálisis; sujeto; leyes; ética de la psicoanálisis; poder familiar.

\section{Résumé}

La destitution du Pouvoir Familier est une action juridique qui impose grand défi aux juristes. Le dialogue avec des divers domaines du savoir peut les aider à amplifier les dicutions à propos de ce sujet. Cet article est basé sur l'interlocution entre le Droit et la Psychanalyse, en analiysant la relation entre le sujet et les lois dans le contexte de la detitution du Pouvoir Familier. On a abordé des questions relatives à la dimension de la Loi de fondation et structuration du sujet et des «lois écrites 》 avec toute leur complexité, errance et carence qu'on peut y vérifier. Dans cette relation on évidencie la violence et la tiranie de la loi, les aspets liés à l'utilisation méchante de la loi, à la destitution subjective et au positionnement du sujet en face aux statuts normatifs. Pour citer Antigone, la dimention tragique du sujet est évoquée à répondre pour son positionnement, soit celui de valider en acte l'injonction inconsciente ou celui de reculer devat elle. Antigone parle de l'autonomie du sujet quand celui-là, à ce momment-là, n'est plus aliéné à l'Autre et peut rendre son désir subjectif en s'opposant à ce qu'il considère injuste ou non humain même que cela soit incrit dans une "légalité ». Le statut se fait dans le sens d'une éthique psychanalytique et de la manière par laquelle le sujet peut être comprit dans sa dimension désirante dans le Droit. La destitution du Pouvoir Familier peut signifier pour quelquesuns l'expropriation de la paternité ou la maternité, l'extinction des liens qui pourraient être préservés à travers le soignement de la famille, pour d'autres est la possibilité d'inscription symbolique par l'instauration d'une Loi qui les inscrit dans l'humain.

Mots-clés: psychanalyse; sujet; lois; éthique de la psychanalyse; pouvoir familier.

O Poder Familiar é entendido como um estatuto jurídico que define a relação paternidade-maternidade e filiação. Segundo Gonçalves (2011a), o Poder Familiar "é o conjunto de direitos e deveres atribuídos aos pais, no tocante à pessoa e aos bens dos filhos menores" (p. 23). A destituição desse estatuto é imputada àqueles que não cumprirem as determinações relacionadas aos cuidados da criança e do adolescente nos termos da lei. As hipóteses de destituição são exaustivas, podendo ocorrer nos casos de castigos imoderados, abandono, atos contrários à moral e aos bons costumes, e descumprimento injustificado dos deveres e obrigações, como sustento, guarda e educação (Gonçalves, 2011b).

No entanto, é comum que se observe nesse contexto a existência de casos de prova mal formada, prova mal produzida e precária, em que, mesmo assim, ajuíza-se temerariamente a ação de destituição do Poder Familiar (Fonseca, 2000). De acordo com Elias (2012), há que se considerar a precipitação nos casos de destituição. Muitos profissionais da área agem dessa forma, justificandose nos interesses da criança, apressando o processo de entrega em adoção, não oferecendo caminhos para que os pais biológicos mantenham a criança junto a si, ou ainda que tenham a possibilidade de repensar sua decisão ou de vivenciar seu luto.

Azambuja (2004) coloca que uma das tarefas mais desafiadoras para os profissionais do Direito reside em identificar o melhor interesse da criança, especialmente nas demandas que aportam ao Poder Judiciário, envolvendo 
pedido de suspensão ou destituição do Poder Familiar. Elias (2012) destaca a carência de estudos sistematizados sobre os motivos desencadeadores dos acolhimentos e das destituições, de modo a esclarecer com profundidade as causas, percursos e negociações que geraram a perda do Poder Familiar. Pouco se sabe sobre as famílias que deixaram seus filhos para adoção, sua história, seus familiares, possíveis abandonos vivenciados, tentativas ou não de permanecer com a criança, entre outras. Isso em decorrência de processos mal formulados ou incompletos em suas investigações e estudos.

Indagações acerca do que causa a entrega de uma criança deveriam suscitar esforços para um aprofundamento na compreensão dos aspectos que envolvem essa decisão e gerar pensamentos críticos sobre situações que influenciam as atitudes destes sujeitos. Minimizar os motivos dos acolhimentos, bem como os aspectos relacionados aos mesmos, significa provocar a perpetuação do silêncio e da violência observados nesse contexto.

$\mathrm{Na}$ perspectiva psicanalítica, a destituição do Poder Familiar configura-se como o rompimento de vínculos, não apenas jurídicos, mas também, e principalmente, afetivos. Nesse sentido, torna-se relevante a discussão sobre as reverberações dessa intervenção para a família, bem como a reflexão sobre formas de atuação alternativas ao rompimento desses vínculos.

Este trabalho busca discutir a relação do sujeito com as leis no contexto da destituição do Poder Familiar. Para tal, recorreremos a autores que estabelecem um diálogo entre a Psicanálise e o Direito, auxiliando a pensar a relação do sujeito com as leis, e de que forma esta relação pode se constituir e se articular com os casos de destituição do Poder Familiar.

\section{A Relação do Sujeito com as Leis}

Pereira (2003a, p. 18) argumenta: "É a lei fundante e estruturante do sujeito e, consequentemente, da sociedade, $\mathrm{e}$, obviamente, do ordenamento jurídico [...].”. Aqui, o autor se refere à primeira Lei, recorrendo a Lévi-Strauss, em Estruturas elementares do parentesco, ao demonstrar que o incesto é a base de todas as proibições, constituindo o passo fundamental graças ao qual e, sobretudo, no qual se realiza a passagem da natureza para a cultura. Para o autor, nas proibições totêmicas mais primitivas estaria, então, a origem de todo o ordenamento jurídico.

A relação existente entre a Lei estruturante do sujeito e os ordenamentos jurídicos também é destacada por Oliveira (2012, p. 213):

[...] podemos dizer que o incesto e o parricídio são as bases de todas as proibições culturais, com a Lei fundando não só a estrutura psíquica do sujeito, mas também as condições para que este possa se inserir na sociedade e para que o ordenamento jurídico alcance valor de autoridade. Portanto, do totem às leis estatais uma eternidade histórica e antropológica não dissolveu o vínculo comum que as sustentam, é dizer, a Lei do Pai.

Essa Lei, que para Elia (2007) se deve escrever com letra maiúscula por seu caráter fundamental e unitário, denominada por Freud de Lei da Castração e por Lacan de Lei do Pai, promove a inscrição do indivíduo como sujeito falante na cultura e castrado no desejo. De acordo com Guyomard (2007), a lei, no sentido da linguagem, institui o que Lacan chama de desejo; se fizermos do desejo não um elemento biológico ou pulsional, mas o efeito da linguagem sobre o sujeito, e, num outro sentido, a inscrição do sujeito na linguagem. Assim, o desejo nasce da linguagem e com a linguagem. "A partir do momento em que o sujeito fala, ele já está marcado pela lei, já está na lei da linguagem" (Guyomard, 2007, p. 29).

De certo modo, é tradicional, no campo de interação entre Direito e Psicanálise, o uso dos termos Lei e leis para diferenciar o que seria a Lei simbólica, mencionada anteriormente, e as leis sociais ou particulares, também chamadas de leis escritas (Oliveira, 2012). As duas formas de "leis" não estão posicionadas de modo estanque ou incomunicáveis, mas interagem de formas diversas no sujeito e na sociedade. Porém, segundo Pereira (2003b), há uma hierarquia simbólica entre elas, ou seja, é pela Lei que o sujeito entra nas leis. Sua inscrição como sujeito falante na cultura e castrado no desejo se configura como pré-condição para que os enunciados jurídicos efetuem sua operação de normalização. É exatamente porque o sujeito é marcado pela Lei do Pai que são possíveis as leis da sociedade onde ele vive e o estabelecimento de ordenamentos jurídicos.

Guyomard (2007) também propõe a distinção do valor da Lei e das leis, apesar de conceber a existência de uma relação recíproca entre as duas dimensões das "leis". Para ele, em um polo, temos as leis, com toda a complexidade, errância e carência que podemos constatar; em outro polo, temos o que chamamos de Lei, o que Lacan chama de lei da linguagem, lei simbólica. O autor destaca também a dupla natureza da relação do sujeito com as leis: "Com efeito, a lei nos protege e, por isso, nós a invocamos, ao mesmo tempo, ela nos violenta e nós a recusamos. Há uma violência da lei, uma tirania das leis [...]" (Guyomard, 2007, p. 7).

Para Oliveira (2012), proteção e tirania da lei são critérios avaliativos resultantes do como da relação entre Lei e leis, das maneiras pelas quais os filhos instauram subjetivamente a Lei do Pai como lei do interdito do gozo, e dela fazem o ponto de partida para a internalização de outras leis, comportando o desejo de segui-las ou rejeitá-las na ambivalência de seus sentimentos de admiração e ódio.

Assim, Guyomard (2007, p. 8) continua dizendo: 
[...] a lei, desse ponto de vista, é sempre em parte externa, ou seja, ela é sempre em parte imposta, é sempre um constrangimento, uma imposição. E podemos nos perguntar porque a suportamos: pela simples razão de que a recebemos do exterior, dos outros, e mesmo do grande Outro, para falar em termos lacanianos; e esta lei é também interna e, como lei interna, ela se manifesta como um certo número de imposições e proibições internalizadas.

Entendemos, então, que há uma relação intrínseca entre Lei e leis, no sentido de que o relacionamento do sujeito com as leis é mediado por sua inscrição na Lei simbólica, havendo, portanto, uma primazia da Lei sobre as leis. Essa primazia invoca outra questão: da presença, na Lei, daquilo que uma sociedade considera humano e não-humano, o que pode ou não corresponder ao que ela considera legal e ilegal. Ou seja, uma determinada lei pode ser extremamente não-humana, apesar de legal.

A não-correspondência entre o humano e o legal envolve uma dissonância entre desejo e mandamentos legais, indicando que a Lei opera de modo a manter sempre em aberto a questão dos fundamentos das leis, evitando o legalismo da obediência às leis que retire a responsabilidade individual de cada um no proceder a esse assujeitamento e legitimando, de certa maneira, a invocação do direito de desobediência. Isso significa, para o sujeito, o direito de se fazer outra coisa, diferente daquilo que as leis impõem, de modo a sustentar a autonomia do desejo frente às leis (Oliveira, 2012).

Sobre isso, Guyomard (2007, p. 9) enfatiza os aspectos da não-humanidade das leis, ou seja, o fato de que "muitas leis, que não preveem tudo, [...] feitas para atender a um certo número de interesses, podem perfeitamente, se muitas condições se modificarem, dar lugar a sentenças aberrantes". Isso é denominado pelo autor de utilização perversa da lei, que se caracterizaria pela utilização da lei para um fim que não a motivou em sua origem, ou seja, em desconsideração ao seu espírito, ao que a motivou.

A aplicação maciça de um regulamento jurídico sem a devida singularização e aprofundamento de sua legitimidade em cada caso representa esta perversidade da lei. Para entendermos o sentido desse termo, é preciso retomar o significado do termo "perverso" em Psicanálise, mais especificamente em Lacan (1956-1957/1995), como sendo aquilo que se opõe à Lei, ao humano e sua inscrição na espécie. Assim, uma determinada lei que em certo contexto estaria desempenhando sua função reguladora e ordenadora, em outro contexto pode violentar ou mesmo privar o sujeito de sua condição humana, no sentido da Lei. Ou seja, uma lei pode perfeitamente se opor à Lei, instaurando uma condição perversa.

É dessa forma que o temo perversidade da lei é aqui apreendido, e é assim também que se relaciona com a ética na Psicanálise, uma vez que o sujeito, diante de uma lei não- humana, pode se responsabilizar pelo não assujeitamento a essa lei e sustentar a autonomia de seu desejo frente às leis.

Entendemos que uma lei pode ser extremamente "injusta" e impor ao sujeito uma desapropriação de si, de sua humanidade. É importante refletir sobre como leis válidas e legítimas para situações específicas que requerem sua utilização, podem ser utilizadas de forma acrítica e maciça, com uma apreensão homogeneizante e dessubjetivante do sujeito. Nesse sentido, torna-se pertinente a discussão a respeito da destituição do Poder Familiar e dos sentidos dessa destituição para os sujeitos em questão, não somente para as figuras parentais envolvidas, mas principalmente para as crianças e adolescentes que se veem em situações de separação e rompimento de vínculos afetivos.

\section{A Incorporação do Discurso e a Destituição Subjetiva}

Para Legendre (1983), o sujeito do Direito é um sujeito possuído pelo Direito. O autor faz menção a uma dogmática totalitária do Direito que engendra um saber-fazer-dançar, à sua maneira, a música do Eu absoluto, que pulula pelos infinitos regramentos normativos e que deve ser incorporada por cada sujeito, como forma de reconhecimento de que as leis se tornam ajuda aos sujeitos "[...] para facilitar-lhes não mais se acharem na grande questão do desejo a não ser identificando-se a esse Eu terrível e tranqüilizador [...]" (Legendre, 1983, p. 110).

Warat (1995 citado por Oliveira, 2012) afirma que as chamadas "ciências jurídicas" se estatuem num conjunto de técnicas de "fazer-crer", com as quais conseguem produzir uma linguagem oficial do Direito, integrada a significados tranquilizadores, representações que têm como efeito impedir ampla reflexão sobre as experiências sociopolíticas. Nesse processo, a razão do Estado se identifica com a racionalidade obliteradora do saber jurídico e das leis positivadas, sinalizando maneira de imposição dos interesses institucionais como "fontes" de desejos de submissão que outorgam consistência imaginária ao Estado, tendo em vista o ocultamento da genealogia e do funcionamento institucional do (poder do) discurso.

A questão da adequação ao discurso jurídico é também discutida por Philippi (2001) ao propor que as leis, ao mesmo tempo em que regulam as ações humanas, desenvolvem igualmente um quantum de silêncio que consagra as condições necessárias para o reconhecimento do ordenamento por cada indivíduo. Esse reconhecimento se dá pela adequação subjetiva ao discurso legal, naquilo em que este discurso encarna, imaginariamente para o sujeito, a referência imaginária ao Outro - pai ausente - como único sujeito da lei, responsável pela unidade do poder e pela consagração da autoridade.

Nesse sentido, a contribuição de Oliveira (2012, p. 
206) destaca o assujeitamento do sujeito às lógicas de determinadas leis pela operação de um discurso:

Entre Direito e Psicanálise há um sujeito assujeitado às lógicas de determinadas leis com as quais cada campo opera a construção/legitimação de seu discurso. De um lado, a norma jurídica regula - coercitivamente - as condutas humanas por intermédio de sua positivação, do outro está o desejo e o inconsciente, mas, sobretudo, o Pai, naquilo que ele representa o imperativo da submissão ao Outro para o ingresso do sujeito à ordem simbólica.

Esses autores evidenciam os mecanismos de imposição de um discurso que é incorporado pelo sujeito como forma de submissão ao Outro. Essas contribuições permitem problematizar as situações de destituição do Poder Familiar, de forma especial aquelas que envolvem a "aceitação", o "consentimento pela destituição" por parte dos pais, ou até mesmo as situações de "entrega" do filho para a adoção. Estaria esse sujeito operando pelas vias da autonomia de um sujeito desejante? Ou estaria, antes, "assujeitado" a um discurso de destituição subjetiva? Ou seja, para usar a linguagem de Legendre (1983), dançando uma música à maneira do Outro - nesse caso representado pelo Estado e pelos ordenamentos jurídicos. Que tipo de discurso pode estar sendo incorporado pelo sujeito nestas condições?

Entendemos que o discurso de destituição subjetiva é também um discurso de incapacidade do sujeito, no qual este se vê e se concebe na "não-capacidade", delegando, pela via da alienação no Outro (Estado/Direito) e como forma de não-desamparo, o poder-de-si: "Eu não sou capaz, eu não posso ser pai, eu não posso ser mãe, por isso delego isto ao Outro que pode ser por mim". Sobre isso, Oliveira (2012, p. 220) declara:

[...] cabe ao soberano estatal adequar sua voz numa normatividade que ordena, antes de tudo, o que pode ser considerado bom (lícito) e mau (proibido) na complexidade do agir humano, sustentado pela alienação imaginária do sujeito que o fomenta à incessante busca pela fusão com o desejo do Outro soberano, aderindo às demandas de ordem que este o direciona, de forma a colocar em xeque sua autonomia de ser desejante na medida em que cede de seu desejo pela antevisão ilusória de que a legalidade deste soberano sinaliza o lócus de seu Bem Supremo, ou seja, das garantias de liberdade e felicidade.

Assim, a condição de assujeitamento e de destituição subjetiva possui estreita relação com os processos de alienação, no sentido de incorporação de um discurso "alheio", bem como de cessão ou transferência do "direito de ser" ao outro.

Em sua origem etimológica, a palavra alienação vem do latim alienus, ou seja, "alheio", significando "o que pertence a um outro". No domínio filosófico, refere-se fundamentalmente a uma espécie de atividade na qual a essência do agente é afirmada como algo externo ou estranho a ele, assumindo a forma de uma dominação hostil sobre o agente. Nos mais variados domínios, o termo alienação é utilizado para significar todo o processo mediante o qual o homem deixa de ser autônomo, de ser dono de si mesmo, para se tornar propriedade de um outro - algo ou alguém - que por ele decide acerca da sua vida (Serra, 2008). Destacamos aqui a utilização do termo "alienação" pelo Direito, qual seria a "cedência ou passagem do direito de posse de determinado bem; cessão ou transferência de bens" (Léxico, 2014).

Recorremos ao significado utilizado pelo Direito intencionalmente, pois tal significado denota bem o sentido de posse de si, de sua subjetividade, do "direito de ser" que é "cedido" ao Estado. Mas a cessão não é uma cessão totalmente livre e autônoma, ela é decorrente da incorporação de um discurso de incapacidade do sujeito, de destituição subjetiva, no sentido de que esse sujeito apropria-se de um discurso "alheio" de não-capacidade e de "não-poder-de-si”, reverberando em uma "cessão" de sua própria subjetividade ao outro.

Por isso esse processo constitui-se em uma "destituição subjetiva", visto que essa desapropriação-de-si não acontece pelas vias de autonomia do sujeito, mas pelo processo de alienação, que faz com que este sujeito se torne assujeitado. A incorporação do discurso do outro-jurídico transforma a coerção (imposição) em "desejo" de submissão, fazendo com que o assujeitamento tenha aparência de autonomia, visto se tratar de um assujeitamento escamoteado por um discurso de legalidade e proteção "tranquilizadores" que impedem a reflexão e a subjetivação.

Sobre a incorporação do discurso pelas vias da alienação, temos as formulações de Lacan, que se apropriou deste conceito, transpondo-o para a Psicanálise, procurando dar conta das relações do sujeito ao discurso do Outro, dos processos de alienação/separação na constituição do sujeito (Poli, 2005). Assim, entendemos que, quando o processo de separação (cisão) do sujeito em relação ao Outro fracassa, o sujeito fica incapaz de subjetivar, ou seja, de constituir sua própria subjetividade. Isso ocorre justamente pela impossibilidade de não-alienação em relação ao Outro.

Portanto, quando tratamos a questão da "dessubjetivação" ou da "destituição subjetiva", estamos nos referindo a um processo no qual o sujeito é desapropriado de sua subjetividade pela impossilidade de se "separar" do Outro (Estado/Direito), alienando-se em seu discurso.

Podemos, assim, discutir os aspectos da "destituição subjetiva" não somente nos casos de destituições indevidas, mas também em situações em que o próprio sujeito "abre mão", "espontaneamente", de seu "Poder Familiar". As reverberações disso para a família e, mais especificamente, para a criança, antes, durante e após a destituição, devem 
ser consideradas e debatidas com o propósito de se pensar formas de cuidado que estimulem e promovam a autonomia do sujeito no desenvolvimento de sua paternidade e maternidade.

\section{O Sujeito Desejante no Direito}

Considerados os mecanismos de coerção escamoteada e de incorporação do discurso jurídico-estatal, podemos, assim como Oliveira (2012, p. 206), interrogar "como se pode instaurar relação simbólica com as leis calcadas na autonomia do sujeito desejante no direito".

De acordo com o autor, o desafio que se coloca no sentido da problemática para superação da relação agressiva e assujeitadora com a lei é o de "problematizar o sujeito, não mais dentro da pretensa homogeneidade igualitária dos discursos imaginários, mas na especificidade de sua condição de sujeito desejante no Direito: autor e avalista da legalidade instituída" (p. 222).

Para tanto, é necessário realizar a suspensão da leitura sobre os modelos ideais da normatividade, de forma a provocar o deslocamento ético do contexto dogmático para a focalização de outra via de acesso à ordem jurídica, uma via que considere o sujeito em sua singularidade e em sua subjetividade, rompendo com os processos de mecanizaçãopositivação e homogeneização do sujeito.

Oliveira (2012) fala da necessidade de investir numa autonomia dos sujeitos que parta das elaborações éticas sobre seus desejos e da desmistificação deste lugar último de soberania das leis, fundamentando-se na teoria lacaniana em suas formulações. A ética proposta por Lacan (1960/2008) consiste na passagem da sujeição ao Outro para a separação do Outro, por meio da subjetivação da causa do desejo. A cisão do sujeito inscreve-o numa falta constitutiva que possibilita sua condição de ser falante e desejante. No que falta, abre-se um vazio de incompletude onde a ética da psicanálise atua.

Tradicionalmente, o campo da ética pertence ao domínio da Filosofia, cujo marco zero pode ser situado com a reflexão aristotélica, no século IV a.C. Entretanto, foi em relação à tragédia sofocliana - concebida um século antes do surgimento da reflexão filosófica - que Lacan (1960/2008) procurou demarcar o fundamento de uma ética própria à psicanálise como sendo referida ao desejo (Vorsatz, 2013).

O encaminhamento de Lacan (1960/2008) a propósito da ética da psicanálise foi marcado pela retomada de Antígona, de modo a destacar a inarredável posição ética que orienta sua principal personagem. Antígona, a heroína trágica, decide desobedecer ao decreto de Creonte, recémtornado rei de Tebas, que havia proibido o sepultamento do corpo de Polinices, irmão de Antígona, considerado traidor e, portanto, inimigo da cidade. De acordo com o decreto, o cadáver de Polinices deveria permanecer insepulto para ser devorado por cães e aves de rapina. A filha de Édipo não se curva a essa determinação real e presta as homenagens fúnebres ao irmão, evocando a favor de seu ato leis divinas, não escritas, em resposta à proibição imposta pelo novo soberano. Essa decisão acarreta sua condenação a um sepultamento ainda em vida.

De acordo com Vorsatz (2013), a tensão dramática se estabelece em torno da posição de Antígona e Creonte. Este representa a lei da cidade - o serviço dos bens -, uma vez que seu decreto visa o bem de todos. Antígona, ao contrário, não se orienta por nenhum bem, nem mesmo o próprio. Ela não faz apelo ao universal, antes, sua decisão é singular e, portanto, irreproduzível. O gesto para com o irmão morto é único, pelo qual a jovem tebana responderá integralmente.

Para Guyomard (2007), há na posição de Antígona, em sua recusa, em sua revolta e mesmo em seu desejo, uma forma de rejeição e resistência a tudo o que é imposto em desconsideração ao humano e ao singular. Ela considera que enterrar seu irmão - porque, dizia "é meu irmão" - era uma coisa mais importante, mais vital e fundamental do que submeter-se às leis da cidade. Antígona não pode tolerar o édito de Creonte. Trata-se, para ela, de salvaguardar a humanidade do irmão. Em seu conflito com o rei, Antígona evoca a dimensão do que ela chama de lei: as leis não escritas, as leis simbólicas; e opõe estas leis às leis escritas.

Lacan (1960/2008) assinala que, a contrapelo do encaminhamento filosófico sobre a ética, a perspectiva psicanalítica não é uma especulação, nem se encontra orientada pelo ideal do Bem. Antes, refere-se a uma experiência, à ação, cuja dimensão é fundamentalmente trágica. Discorrendo sobre a ética da psicanálise o autor diz:

[...] não é uma especulação que incide sobre a ordenação [...] do que chamo de serviços dos bens. Ela implica [...] a dimensão que se expressa no que se chama experiência trágica da vida. É na dimensão trágica que nossas ações se inscrevem [...]. (Lacan, 1960/2008, p. 376)

Nessa direção, Vorsatz (2013) afirma que a problemática ética na tragédia antiga não é posta em termos de uma consideração abstrata do "que é o bem, a justiça, a verdade". O "como devo agir" apresenta-se encarnado, e não como uma formulação de caráter abstrato, como no pensamento filosófico sob a fórmula geral "o que é preciso saber para bem se conduzir, isto é, em nome do bem comum". É na tomada de posição do herói que a dimensão ética se apresenta na tragédia, e, portanto, também na psicanálise.

Vorsatz (2013) destaca, em sua obra, a dimensão da responsabilidade do sujeito frente ao seu ato e frente àquilo que o determina. Para a autora, a tragédia articula a relação do homem com o sentido de sua ação, em outras palavras, a função da tragédia antiga é a de "trazer à cena a dimensão ética em ato" (Vorsatz, 2013, p. 45). Para ela, Antígona apresenta o herói diante de uma espécie de escolha forçada, 
de um ato que, levado a termo, resulta em sua própria perda, em relação à qual não pode se furtar.

O sujeito é convocado a responder por sua posição, quer esta tenha sido a de validar em ato a injunção inconsciente, quer tenha sido a de recuar diante dela, "ter cedido de seu desejo", para retomar Lacan (1986, p. 382). A injunção divina presente na tragédia não exime a responsabilidade humana; ao contrário, convoca-a. Cabe ao herói trágico uma posição, ali mesmo onde os deuses impõem, o herói deve se responsabilizar (Vorsatz, 2013).

No caso da heroína Antígona, ela age movida apenas por sua decisão, nas palavras do coro na tragédia, ela é autônomos, aquela que faz sua própria lei (Vorsatz, 2013). Ela não cede de seu desejo e vai de encontro àquilo que não considera humano.

Para Guyomard (2007), Antígona coloca em cena a relação entre a Lei e as leis, bem como a posição e a forma como o sujeito interage simbolicamente com as leis. $\mathrm{O}$ autor destaca a não-humanidade das leis e a possibilidade de recusa destas leis como expressão de um sujeito desejante. A autonomia do sujeito se faz evidenciar quando este, agora não mais alienado ao Outro, pode subjetivar seu desejo, indo de encontro àquilo que considera injusto ou não-humano, mesmo que inscrito numa tal "legalidade".

Oliveira (2012) considera que a travessia psicanalítica que vai da alienação no Outro à separação do Outro é análoga ao percurso que o sujeito do Direito deve proceder para estabelecer seu ser jurídico como sujeito desejante no Direito. O que resulta disso é a responsabilização, apreensão da relação do indivíduo com o desejo do Outro, visto que é convocado a se perceber como alguém que é sujeito de um destino particular que não escolheu - conscientemente -, mas, por mais aleatório e acidental que possa parecer no início, deve, entretanto, subjetivar.

Essa subjetivação do desejo do Outro, processo de confrontação com a alteridade radical no íntimo do sujeito, possibilita-lhe advir como Eu e assumir sua própria causalidade na sensibilidade ética da passagem da posição de vítima do inconsciente para a de responsável por aquilo que o causa, ou melhor, o que no desejo o interpela. Assim, a existência de instrumentos democráticos de participação política permite aos cidadãos modificar uma cultura oficial em um campo cultural de resistência de forma a exigir do Estado um espaço de produção democrática da subjetividade, no qual os cidadãos assumam a estatura de criadores e não mais de consumidores passivos do discurso oficial (Oliveira, 2012).

Isso implica enfatizar a especificidade do desejo, deslocando o eixo das análises centradas na ideia de indivíduos consumidores de normas para a compreensão de "ser" responsável pela produção da legalidade.

Em tudo isso a ética da Psicanálise - de não ceder de seu desejo ante o reconhecimento da Lei e da subjetivação do desejo do Outro - torna-se pressuposto mediador fundamental para que os sujeitos passem do estágio de destinatários passivos dos ditames legais para os de construtores dos vazios dos enunciados jurídicos, verdadeiros interpretes da legalidade aberta e, portanto, criadores da gramática jurídica que faça da (re)pressão do desejo e da (co)ação da Lei os operadores subjetivos para a atribuição dos sentidos a sentimentos. (Oliveira, 2012, p. 229)

Nesse sentido, Guyomard (2007) destaca que o domínio da ética é o domínio da responsabilidade na interpretação e aplicação das leis, o que permite não relativizar as leis, mas situá-las, referi-las a alguma outra coisa e, portanto, poder considerá-las como sendo injustas, o que permite que alguém decida desobedecer ou não aplicar as leis. Desse ponto de vista, o campo da ética é duplo: é, ao mesmo tempo, o campo da responsabilidade e o campo da liberdade - liberdade de desobedecer ou liberdade de escolher aplicar e se conformar à lei, mesmo quando isso significa se impor uma violência, submetendo-se a uma lei contrária aos próprios interesses.

Para o autor, a ética é essencial à questão da humanidade em relação à lei, pois estabelece a mediação em todo campo da relação entre a Lei e as leis, permitindo colocar a questão da perversidade da lei, quando as carências, obscuridades ou a letra da lei são utilizadas contra o próprio espírito da lei.

Entendemos, então, que o sujeito, em sua relação com as leis, é mediado pela ética, o que lhe possibilita sair da posição de sujeito possuído pelo Direito para sujeito desejante no Direito. Isso significa que aquele indivíduo assujeitado a um discurso "alheio" pode advir, através do reconhecimento de si, por meio da cisão em relação ao Outro e da subjetivação do discurso, apreendendo, ao mesmo tempo, sua liberdade e sua responsabilidade frente às escolhas e ações que empreende.

\section{A Função Simbólica do Direito}

As leituras realizadas em busca da compreensão da relação do sujeito com as leis fizeram emergir algumas perguntas a respeito da função das leis e do Direito na constituição e na história do sujeito. Tais indagações questionavam se o Direito teria apenas essa função de assujeitamento e destituição do sujeito ou se sua existência poderia estar também ligada a alguma outra "função" que carregasse em si um sentido legítimo em sua relação com o sujeito e sua humanidade. $O$ trabalho de Hélène CazouxCharles (2007), psicanalista do Serviço Social da Infância e Juíza da Vara de Família em Paris, nos fornece algumas pistas a esse respeito.

Influenciada pelas obras de Freud - mais 
especificamente Totem e tabu (1913/1974) e Mal-estar na civilização (1930/1974), que abordam a questão da lei simbólica, do interdito e da passagem do homem para a cultura -, a autora desenvolveu a ideia de que o Judiciário poderia ter outra função para além da normatização de comportamentos - uma função de humanização do ser e de civilização da sociedade, a qual ela denominou de "função simbólica do direito".

Charles (2007, p. 111) defende a ideia de que o juiz pode exercer uma "função parental", o papel de uma instância paterna separadora e diferenciadora:

Desde que assumi minha função como Juiz da Infância e Juventude, sustentei o desafio de ocupar uma função parental. Mais precisamente, apoiando-me no texto Mal-estar na civilização, pensava que o direito deveria significar a falta necessária a toda vida humana e que o Juiz deveria representar junto aos pais e filhos - toda uma ordem familiar - o papel de uma instância paterna separadora e diferenciadora. Eu colocava, assim, em um mesmo nível de igualdade simbólica, o pater famílias e o Juiz, sendo que, na presença das famílias que recebia se afrontavam duas representações de paternidade: uma de legalidade, que eu deveria encarnar; a outra, falível ou mesmo louca.

A falibilidade paterna mencionada por Charles the parece advinda da impossibilidade de os pais concretos exercerem o papel de limite, de princípio separador, de inscrição do sujeito no humano. Assim, para ela, convinha que o juiz, a partir de uma análise da realidade familiar, definisse o momento e a maneira, sempre diferentes em cada caso, em que ele deveria impor uma lei para, em suas palavras, "forçar o humano" (Charles, 2007, p. 111).

Reconhecia, no entanto, a complexidade e o desafio que se colocava diante dessa função, que a solicitava definir uma ideia do "justo" sobre a qual ela pudesse apoiar sua legitimidade ao "forçar" um destino familiar. Como "definir o justo preço que cada indivíduo deve pagar para entrar na ou voltar à civilização? Como poderia avaliar, o mais exatamente possível, a dívida que cada um devia pagar para deixar a barbárie e entrar na ordem do humano?" Eram alguns questionamentos levantados pela autora.

Dunley (2011) também interroga sobre como "fazer leis", como fazer um direito justo, aplicado em relação a uma "natureza humana" que é desviante, indomável, agida pelo inconsciente: "Qual o preço justo a fazer pagar um sujeito que agiu fora da lei por uma recondução à civilização, atravessada agora por este humano, cuja condição é trágica, dilacerada, desviante e indomável por conta de sua natureza pulsional?" (Dunley, 2011, p. 139). São questões em que o Direito e a Psicanálise podem avançar juntos, de acordo com a autora.

Na opinião de Charles (2007), a lei deve ser entendida pelo juiz como emanação contemporânea do interdito fundador de toda sociedade (interdito de assassinato e de incesto), cuja mediação e interpretação lhe cabem. A autora é enfática ao dizer e reafirmar que se posiciona em "oposição aos que pregam o desejo contra a lei, a liberdade contra o direito, a civilização pela morte do Juiz" (Charles, 2007, p. 113). Mas esclarece que o direito exercido por um juiz fora de seu lugar concreto e também simbólico, utilizado como técnica de regulação social ou como insígnia a combater, nada pode fazer pelo sujeito.

Em sua vasta experiência em Vara de Família e em processos de destituição do Poder Familiar, Charles traz uma reflexão sobre as etapas de investigação e de julgamento nestes processos. Menciona que, ao convocar uma equipe técnica (psiquiatra, psicólogo e assistente social), o que lhe interessa é o que ela chama de "formulação da questão" (Charles, 2007, p. 125). Não se trata aqui de relatar a monstruosidade da mãe ou a violência do pai, a questão está em detectar, a partir da análise de um destino familiar, onde se abre a brecha pela qual se insere a barbárie ou a impossibilidade, para os pais, de transmitirem suas dívidas de humanidade a seus filhos.

Nesse sentido, a autora coloca que o crime contra a espécie se situa para além do biológico. "Pior do que fazer desaparecer ou maltratar fisicamente seres humanos é jamais permitir aos filhos se tornarem sujeitos, enquanto crianças identificadas numa ordem genealógica e, pior ainda, não lhes permitir encontrar lugar, enquanto seres humanos, na ordem da espécie" (Charles, 2007, p. 125).

Referindo-se à investigação, Charles menciona casos em que um curto-circuito na maneira de conduzir o questionamento pode impedir que se evidencie um crime mais grave que os crimes biológicos: o crime de tudo o que poderia representar a grande "ausência paterna", no sentido do que pode instituir o humano. Chega a dizer que, por falta de formulação da questão, é impossível dar estatuto ao perigo que se transmite tranquilamente dos avós aos pais e dos pais aos filhos, por um fenômeno que ela chama de parentalização. Sem formulação da questão, a tragédia se repete, do mesmo modo que a autoridade jurídica gagueja separações e separações, sem jamais se questionar acerca daquilo que escapa de suas decisões.

\section{Considerações Finais}

A relação do sujeito com as leis é marcada por uma dupla inscrição: a inscrição de uma humanidade, mas também a inscrição de uma tirania e uma violência imposta ao sujeito a despeito de seu desejo. A análise dessa relação nos conduziu a pensar a articulação da Lei com as leis, da Lei fundante na constituição do sujeito com as leis escritas, que estabelecem para o sujeito regulamentos e normas a serem seguidos. As duas formas de "leis" não estão posicionadas 
de modo estanque, ou incomunicáveis, mas interagem de diversas formas no sujeito e na sociedade. Há, porém, uma hierarquia simbólica entre elas, ou seja, é pela Lei que o sujeito entra nas leis.

Nessa relação, evidenciou-se a não-correspondência entre o que se pode considerar humano e o que se inscreve em uma legalidade, de modo que uma determinada lei pode ser extremamente não-humana, apesar de legal. Esse aspecto caracteriza a perversidade de lei quando esta é utilizada para um fim que não a motivou em sua origem. Assim, a Lei opera de modo a manter sempre em aberto a questão dos fundamentos das leis, evitando o legalismo da obediência que retire a responsabilidade individual de cada um no proceder a esse assujeitamento e legitimando, de certa maneira, a invocação do direito de desobediência. Isso significa o direito de se fazer outra coisa diferente daquilo que as leis impõem, de modo a sustentar a autonomia do desejo frente às leis.

Há, na relação do sujeito com o Direito, um assujeitamento pelas vias da alienação e da destituição subjetiva. As chamadas ciências jurídicas se estatuem num conjunto de técnicas com as quais conseguem produzir uma linguagem oficial integrada a significados tranquilizadores, representações que têm como efeito impedir ampla reflexão sobre as experiências sociopolíticas. Nesse processo, a razão do Estado se identifica com a racionalidade obliteradora do saber jurídico e das leis positivadas, escamoteando a imposição dos interesses institucionais como "fontes" de desejos de submissão.

Isso nos convoca a problematizar as situações de destituição do Poder Familiar, tema central deste estudo, através do deslocamento da universalização e homogeneização do sujeito para um posicionamento em ato e singular. Estaria este sujeito, que foi destituído de sua paternidade e de sua maternidade, operando pelas vias da autonomia e do desejo? Ou estaria, antes, assujeitado a um discurso de destituição subjetiva, através dos mecanismos de alienação e submissão a este Outro absoluto representado pelo poder do Estado e do Direito?

Entendemos que o sujeito, em sua relação com as leis, é mediado pela ética, o que lhe possibilita sair da posição de sujeito possuído pelo Direito para sujeito desejante no Direito. Isso significa que aquele indivíduo assujeitado a esse discurso "alheio" pode advir, através do reconhecimento de si, por meio da cisão em relação ao Outro e da subjetivação do discurso, apreendendo, ao mesmo tempo, sua liberdade e sua responsabilidade frente às escolhas e ações que empreende.

Na singularidade trágica de cada família e de cada sujeito implicado nessa tragédia, Charles (2007) nos convoca a pensar a forma como ela concebe a função de um juiz na vida e na história de uma família. Para a autora, o juiz possui o encargo e a responsabilidade de exercer uma função, que não se limita à imposição de normativas de controle e punição, mas se refere muito mais a uma função de humanização do ser e de civilização da sociedade, a qual ela denominou de "função simbólica do direito".

As formulações de Charles (2007) no que concerne à função simbólica do direito em articulação com o que outros autores discutem sobre ouso perverso da lei e a incorporação do discurso jurídico por parte do sujeito nos fornecem um delineamento de possíveis entradas ou inserções do direito na vida privada de um indivíduo ou de uma família.

A leitura de Guyomard (2007), Legendre (2004), Oliveira (2012), dentre outros, permite tecer considerações a respeito da exacerbação do controle do Estado sobre a família e a vida privada do indivíduo, bem como discutir as questões relacionadas ao aspecto ilegítimo e perverso na utilização das leis, quando estas exercem uma função de assujeitamento e destituição subjetiva, colocando o sujeito em um lugar de incapacidade e não-humanidade.

$\mathrm{Na}$ outra face, temos a função do Estado de proteger e dar condições para que a criança se desenvolva em ambiente saudável, capaz de salvaguardar seus direitos de sujeito e de cidadão. Essa perspectiva é evidenciada por Charles (2007) quando destaca o exercício do juiz em sua função de legitimidade, solicitado simbolicamente a ocupar o lugar de "separador", daquele que inscreve o sujeito na espécie, em sua humanidade, exercendo uma função diferenciadora do indivíduo enquanto sujeito, a função paterna.

Tais articulações impõem um desafio de extrema complexidade aos que "exercem" o Direito: encontrar ou reencontrar, na singularidade de cada caso, o sentido de sua função e de seu lugar na vida dos sujeitos, ou na vida de uma família. A destituição do Poder Familiar pode significar, para alguns, a desapropriação de si enquanto pai e mãe, a "destruição" de laços e vínculos que poderiam ser preservados através de medidas de cuidado à família. Para outros, pode significar a possibilidade de inscrição simbólica, pela instauração de uma Lei que os inscreve no humano, através não da "simples" retirada de um jogo familiar não-humano, mas principalmente pela possibilidade de representar o lugar simbólico de humanidade.

\section{Referências}

Azambuja, M. R. F. (2004). Violência sexual intrafamiliar: É possivel proteger a criança? Porto Alegre: Livraria do Advogado.

Charles, H. C. (2007). O juiz da infância e da juventude garante da ordem pública genealógica ou aprendiz de cozinheiro? In S. Altoé (Org.), A Lei e as leis (pp. 109134). Rio de Janeiro: Revinter.

Dunley, G. P. (2011). Psicanálise e Direito: um diálogo possível? Revista Tempo Psicanalítico, 43(1), 
131-154. Recuperado de http://pepsic.bvsalud. org/scielo.php? script $=$ sci_arttext\&pid $=$ S0101$48382011000100008 \& \operatorname{lng}=$ pt\&tlng $=$ pt.

Elia, L. (2007). O sujeito - ainda e sempre em questão. In S. Altoé (Org.), A Lei e as leis (pp. 85-96). Rio de Janeiro: Revinter.

Elias, S. A. T. (2012). Enfrentamento e rupturas: O percurso da mulher em suas vicissitudes com a maternidade. Encontro: Revista de Psicologia, 15(23), 93-104. Recuperado de http://www.sare.anhanguera.com./ index.php/rencp/article/view/4532.

Fonseca, A. C. L. (2000). A ação de destituição do Pátrio Poder. Revista Igualdade, 8(29), 1-41.

Freud, S. (1974). Totem e tabu. In Edição Standard Brasileira das Obras Psicológicas Completas de Sigmund Freud (Vol. 13, pp. 6-102). Rio de Janeiro: Imago. (Originalmente publicado em 1913)

Freud, S. (1974). O mal-estar na civilização. In Edição Standard Brasileira das Obras Psicológicas Completas de Sigmund Freud (Vol. 21, pp. 9-89). Rio de Janeiro: Imago. (Originalmente publicado em 1930)

Gonçalves, C. R. (2011a). Direito Civil Brasileiro: direito de família ( $8^{\text {a }}$ ed., Vol. 6). São Paulo: Saraiva.

Gonçalves, E. O. (2011b). Estatuto da Criança e do Adolescente Comentado. Campinas, SP: Ed. Servanda.

Guyomard, P. (2007). A Lei e as leis. In S. Altoé (Org.), $A$ Lei e as leis (pp. 01-59). Rio de Janeiro: Revinter.

Lacan, J. (1995). O Seminário,livro 4: A relação de objeto (1956-1957). Rio de Janeiro: Jorge Zahar.

Lacan, J. (2008). O Seminário, livro 7: A ética da psicanálise (1959-60). Rio de Janeiro: Jorge Zahar.

Legendre, P. (1983). O amor do censor: ensaio sobre a ordem dogmática. Rio de Janeiro: Forense universitária: Colégio Freudiano.

Legendre, P. (2004). Seriam os fundamentos da ordem jurídica razoáveis? In S. Altoé (Org.), Sujeito do Direito, sujeito do Desejo: direito e psicanálise (pp. 15-28). Rio de Janeiro: Revinter.

Léxico: Dicionário de Português Online. (2014). Recuperado de http://www.lexico.pt/alienacao/
Oliveira, A. C. (2012). Estado, Direito e Sujeito contribuições da psicanálise freudo-lacaniana. REDUnB, 10, 205-234. Recuperado de http://seer.bce. unb.br/index.php/redunb/article/view/7101

Pereira, R. C. (2003a). Direito de família: uma abordagem psicanalitica (3a ed. revista, atualizada e ampliada). Belo Horizonte: Del Rey.

Pereira, R. C. (2003b). A primeira lei é uma lei de Direito de Família: a lei do pai e o fundamento da lei. In G. C. Groeninga, \& R. C. Pereira (Orgs.), Direito de família e psicanálise - rumo a uma nova epistemologia (pp. 17-29). Rio de Janeiro: Imago.

Philippi, J. N. (2001). A lei: uma abordagem a partir da leitura cruzada entre Direito e Psicanálise. Belo Horizonte: Del Rey.

Poli, M. C. (2005). "Alienação" na psicanálise: a pré-história de um conceito. Psichê, 9(16), 133-152. Recuperado de http://pepsic.bvsalud.org/scielo.php?pid=S1415$11382005000200009 \&$ script $=$ sci_arttext

Serra, J. M. P. (2008). Alienação. Covilhã: Universidade da Beira Interior. Recuperado de http://www.lusosofia. net/textos/serra_paulo_alienacao.pdf.

Vorsatz, I. (2013). Antígona e a ética trágica da psicanálise. Rio de Janeiro: Zahar. 
Endereço para correspondência:

Suziani de Cássia Almeida Lemos

Endereço: Avenida JK, 1015, apto. 402, Bloco E, Bairro:

Jardim América. Itumbiara/GO, CEP: 75.523-425.

E-mail: suzianilemos@gmail.com

Endereço para correspondência:

Anamaria Silva Neves

Endereço: Av. dos Jardins, 250/105, Bairro: Nova

Uberlândia. Uberlândia/MG, CEP: 38.412-639.

E-mail: anamaria@umuarama.ufu.br

\section{Endereço para correspondência:}

João Luiz Leitão Paravidini

Endereço: Universidade Federal de Uberlândia - Instituto de Psicologia, Av. Uirapuru, 934, Cidade Jardim.

Uberlândia/MG, CEP: 38.412-166.

E-mail: paravidini@ufu.br 